\title{
Efeito de Substratos sobre a Germinação de Uredosporos e Comprimento de Tubos Germinativos de Puccinia triticina
}

\author{
Erlei M. Reis \& Rudinei L. Richter \\ Faculdade de Agronomia e Medicina Veterinária, Universidade de Passo Fundo, CEP 99001-970, \\ Passo Fundo, RS, e-mail: erlereis@tpo.com.br
}

Autor para correspondência: Erlei Melo Reis

REIS, E.M. \& RICHTER, R.L. Efeito de substratos sobre a germinação de uredosporos e comprimento de tubos germinativos de Puccinia triticina. Fitopatologia Brasileira 32:075-078. 2007.

\section{RESUMO}

O presente trabalho teve como objetivo testar alguns substratos para elevar a taxa de germinação de uredosporos e promover um maior crescimento dos tubos germinativos do agente causal da ferrugem da folha do trigo (Puccinia triticina) e compará-los ao substrato água-ágar considerado padrão. Foram testados os substratos: água-ágar, batata sacarose ágar (BSA), 1/4 BSA, dextrose-ágar, frutose-ágar, manitol-ágar, sacarose-ágar, infusão de folhas de trigo-ágar e extrato de folhas de trigo-ágar. Após a deposição dos uredosporos nas placas de petri contendo os substratos, o material foi incubado em câmara de crescimento, no escuro a $20^{\circ} \mathrm{C}$, por 6, 12 e 24 horas. Avaliou-se a germinação dos uredosporos e mediuse o comprimento dos tubos germinativos. As médias de germinação e de comprimento dos tubos germinativos foram comparadas pelo teste de Duncan a 5\%. Os valores mais elevados de germinação de uredosporos e do comprimento do tubo germinativo foram observados nos substratos infusão de folhas de trigo-ágar e extrato de folhas de trigo-ágar.

Palavras-chave adicionais: ferrugem da folha, Triticum aestivum.

\begin{abstract}
Effect of substrata on germination of urediniospores and on length of germ tube of Puccinia triticina

The objective of this study was to test a methodology which provides a better germination rate of urediniospores and higher growth of germ tubes of the causal agent of wheat leaf rust (Puccinia triticina) in relation to the water-agar substratum. The following substrata were tested: water-agar, potato-sucrose-agar (PSA), 1/4 PSA, dextrose-agar, fructoseagar, manitol-agar, sucrose-agar, wheat-leaves infusion-agar and, wheat-leaves extract-agar. A urediniospore suspension was poured on the substrata in Petri dishes and incubated in growth room, in darkness at $20^{\circ} \mathrm{C}$, for 6,12 and, 24 hours. Germination of urediniospores and length of the germ tube were assessed. Means for germination and germ tube length were compared by Duncan test at 5\%. The highest germination rate and germ tube growth were observed on the wheatleaves infusion and wheat-leaves extract-agar substrata.
\end{abstract}

Additional keywords: leaf rust, Triticum aestivum.

\section{INTRODUÇÃO}

A cultura do trigo se constitui na melhor alternativa econômica para cultivo de inverno no sul do Brasil(Anônimo, 2003). O sistema de produção de trigo exige um alto grau de tecnificação para garantir produtividade e qualidade da produção que possibilitem resultado econômico ao produtor e competitividade vantajosa num mercado cada vez mais globalizado. Há, contudo, dificuldades quanto à produção de cereais de inverno, as quais se devem a ocorrência de doenças que estão relacionadas com as adversidades climáticas ocorrentes no sul do Brasil. As chuvas freqüentes durante o espigamento, aliada à temperatura alta, contribuindo para o ataque severo de doenças, constitui-se na principal causa da instabilidade das safras (Reis et al., 2001).

Dentre as doenças do trigo destaca-se a ferrugem da folha causada pelo fungo Puccinia triticina Ericks. (Samborski, 1985).

As principais estratégias de controle da ferrugem da folha do trigo concentram-se no desenvolvimento de cultivares com resistência genética e na aplicação de fungicidas nos órgão aéreos quando a intensidade da doença atingir o limiar de ação. Segundo Barcellos et al. (1997), apesar dos esforços da pesquisa, a resistência à ferrugem da folha não é durável, e por isso, freqüentemente os cultivares cultivados como resistentes tem os mecanismos de defesa vencidos pelas novas raças virulentas de $P$. triticina.

Na safra 2002 foi observado na região dos Campos Gerais do Paraná, que um fungicida do grupo dos triazóis não controlou satisfatoriamente a ferrugem da folha. Esse fato foi observado no cultivar trigo OR-1 tendo-se levantado a hipótese de que poderia ter surgido uma nova raça do fungo com insensibilidade ao princípio ativo daquele fungicida.

Uma das maneiras de se avaliar a sensibilidade de um fungo a substâncias químicas é através de experimentos conduzidos em laboratório com substrato artificial, onde se quantifica o comportamento da germinação dos esporos ou o crescimento do micélio sobre substratos suplementados com concentrações crescentes de princípios ativos de fungicidas. Um substrato comumente utilizado é o meio 
ágar-água (Torgeson, 1967). Porém, neste substrato a taxa de germinação de urediniosporos das ferrugens é reduzida, provavelmente por serem parasitas biotróficos. Baseado no relatado de Suzuki et al. (1998), levantou-se a hipótese que exsudatos foliares do trigo pudessem estimular a germinação de uredosporos "in vitro".

Este trabalho teve por objetivo identificar um substrato que proporcione melhor taxa de germinação de uredosporos e promova um maior crescimento dos tubos germinativos dos esporos de $P$. triticina em relação ao substrato padrão ágar-água.

\section{MATERIAL E MÉTODOS}

O experimento foi conduzido no laboratório de Fitopatologia da Faculdade de Agronomia e Medicina Veterinária da Universidade de Passo Fundo. Foram utilizados nove substratos: ágar-água (12 $\mathrm{g}$ de ágar/litro de água), batata-sacarose-ágar (200 g de batata, $20 \mathrm{~g}$ de sacarose e $12 \mathrm{~g}$ de ágar/litro de água), batata-sacarose-ágar (1/4), sacarose-ágar (12 g de agar; 11,88 g de sacarose em 1 litro de água), frutose-ágar (12 $\mathrm{g}$ de agar; $12,5 \mathrm{~g}$ de frutose em 1 litro de água), dextrose-ágar (12 g de agar; 12,5 g de dextrose por litro de água), manitol-ágar (12 g de agar; 12,64 g de manitol por litro de água), infusão de folhas de trigo ágar (12 g de ágar, $1 \mathrm{~g}$ de folhas de trigo por litro de água) e extrato de folhas de trigo ágar (12 g de ágar, $1 \mathrm{~g}$ de folhas de trigo por litro de água). Foram utilizadas igualmente para todos os substratos $5 \mathrm{~g}$ de carbono por litro para cada fonte. A unidade experimental foi constituída de uma placa de petri. Foram utilizadas quatro repetições para cada tratamento.

Os uredosporos, coletados nas uredopústulas de folhas de trigo naturalmente infectadas, foram suspensos e diluídos em água para obtenção de uma concentração conhecida (aproximadamente 500 uredoporos/placa) e vertido $1 \mathrm{~mL}$ da suspensão sobre os substratos. As placas foram incubadas em câmaras de crescimento, à temperatura de $20^{\circ} \mathrm{C}$, no escuro, por períodos de 6,12 e $24 \mathrm{~h}$.
A germinação dos uredosporos foi avaliada em microscópio óptico pela varredura da placa, se examinado 50 uredosporos por repetição. Considerou-se como germinado o uredosporo que apresentou o tubo germinativo mais longo do que o seu maior diâmetro (Sharvelle,1969). O comprimento do tubo germinativo foi mensurado com um micrômetro adaptado a ocular do microscópio.

Os experimentos foram repetidos duas vezes. $\mathrm{Na}$ análise estatística os dados foram transformados em (), por não apresentarem distribuição normal, decorrente do aparecimento de porcentagens próximas a zero em dois tratamentos. Os dados foram analisados seguindo o modelo experimental fatorial num arranjo de tratamentos completamente casualizados sendo submetidos ao teste de comparação de médias (Duncan a 5\%).

\section{RESULTADOS E DISCUSÃO}

De acordo com os resultados da analise de variância, houve interação significativa entre substratos e tempo de exposição, tanto para taxa de germinação de uredosporos como para o comprimento do tubo germinativo. Nesse sentido, para o tempo de exposição de $6 \mathrm{~h}$ o substrato que apresentou a maior taxa de germinação de uredosporos, foi o extrato de folhas de trigo-ágar (63,61\% de germinação), porém não diferenciou significativamente dos tratamentos dextrose-ágar, sacarose-ágar, batata-sacarose-ágar e batata-sacarose-ágar (1/4) (Tabela 1). A menor taxa de germinação para o tempo de exposição de $6 \mathrm{~h}$ foi obtida no substrato manitol-ágar ( $1 \%$ de germinação), não diferindo significativamente do substrato frutose-ágar. Já no tempo de exposição de $12 \mathrm{~h}$, o substrato que obteve a melhor taxa de germinação foi a infusão de folhas de trigo-ágar $(61,35 \%$ de germinação), não diferenciando significativamente dos substratos extrato de folhas de trigo-ágar, dextroseágar, sacarose-ágar, batata-sacarose-ágar (1/4) e água-ágar (Tabela 1). A menor porcentagem absoluta de germinação para o tempo de exposição de $12 \mathrm{~h}$ foi obtida no substrato

TABELA 1 - Efeito de substratos e do tempo de exposição na germinação (\%) de uredosporos de Puccinia triticina

\begin{tabular}{lllll}
\hline \hline \multirow{2}{*}{ Substratos } & \multicolumn{3}{c}{ Tempo de exposição (h) } & Média \\
\cline { 2 - 4 } & \multicolumn{1}{c}{$\mathbf{6}$} & $\mathbf{1 2}$ & $\mathbf{2 4}$ & \\
\hline 1- Água -ágar & $37,50 \mathrm{Ac}$ & $49,50 \mathrm{Aab}$ & $43,89 \mathrm{Aab}$ & 43,63 \\
2- Batata -sacarose -ágar (1/4) & $50,45 \mathrm{Aabc}$ & $54,90 \mathrm{Aab}$ & $49,29 \mathrm{Aa}$ & 51,55 \\
3- Batata -sacarose -ágar & $47,50 \mathrm{Aabc}$ & $42,05 \mathrm{Ab}$ & $41,64 \mathrm{Aab}$ & 43,73 \\
4- Sacarose -ágar & $48,06 \mathrm{Aabc}$ & $49,35 \mathrm{Aab}$ & $44,82 \mathrm{Aab}$ & 47,41 \\
5- Dextrose -ágar & $56,00 \mathrm{Aab}$ & $50,63 \mathrm{Aab}$ & $46,64 \mathrm{Aab}$ & 51,09 \\
6- Frutose -ágar & $2,00 \mathrm{Bd}$ & $42,55 \mathrm{Ab}$ & $33,32 \mathrm{Ab}$ & 25,96 \\
7- Manitol -ágar & $1,00 \mathrm{Cd}$ & $29,56 \mathrm{Bc}$ & $49,64 \mathrm{Aa}$ & 26,73 \\
8- Infusão de folhas de trigo-ágar & $44,60 \mathrm{Bbc}$ & $61,35 \mathrm{Aa}$ & $55,71 \mathrm{ABa}$ & 53,89 \\
9- Extrato de folhas de trigo-ágar & $63,61 \mathrm{Aa}$ & $53,67 \mathrm{Aab}$ & $48,18 \mathrm{Aa}$ & 55,15 \\
\hline Média & 38,97 & 48,17 & 45,90 & 44,35 \\
\hline
\end{tabular}

Médias seguidas de mesma letra maiúscula na linha e minúscula na coluna não diferem significativamente pelo teste Duncan a 5\%. 
manitol-ágar com 29,56\% de germinação. No tempo de exposição de $24 \mathrm{~h}$, o substrato infusão de folhas de trigoágar proporcionou a melhor taxa de germinação $(55,71 \%$ de germinação), não diferindo significativamente dos demais substratos, com exceção do substrato frutose-ágar. A menor taxa de germinação ocorrida no tempo de exposição de 24 h foi no substrato frutose-ágar com 33,32\% de germinação, não diferindo significativamente dos substratos água-ágar, batata-sacarose-ágar, sacarose-ágar e dextrose-ágar.

Os tratamentos não apresentaram diferenças significativas quanto à porcentagem de uredosporos germinados devido a variação no tempo de exposição, com exceção dos tratamentos frutose-ágar e infusão de folhas de trigo-ágar, os quais apresentaram a maior germinação de uredosporos em ambos os casos, com 12 e $24 \mathrm{~h}$ de exposição. O substrato manitol-ágar proporcionou a maior taxa de germinação no tempo de exposição de $24 \mathrm{~h}$.

A máxima germinação detectada ocorreu no substrato extrato de folhas de trigo-ágar com $63,61 \%$ com $6 \mathrm{~h}$ de exposição. Esse número ainda pode ser considerado baixo e, portanto, outros substratos e condições ambientais devem ser pesquisados para melhorar ainda mais a taxa de germinação. Por outro lado, a menor germinação foi detectada no substrato manitol-ágar com $1 \%$ de viabilidade com apenas 6 $\mathrm{h}$ de exposição, não diferindo significativamente do substrato frutose-ágar com $6 \mathrm{~h}$ de exposição.

O substrato manitol-ágar foi o único que respondeu positiva e significativamente ao aumento do tempo de exposição ao incrementar a germinação em função desta variável. Com 6 h houve uma germinação de 1,0\%, $12 \mathrm{~h}$ germinação de 29,6 \% e 24 h germinação de $496 \%$. No entanto, em trabalhos de pesquisa o desejável é obter a máxima germinação com o menor tempo de exposição. Nesse sentido o melhor substrato foi o extrato de folhas de trigo-ágar (Tabela 1).

Quanto ao efeito dos substratos no crescimento dos tubos germinativos, observa-se que o maior crescimento do tubo germinativo ocorreu com a utilização do substrato extrato de folhas de trigo-ágar ( $38,7 \mu \mathrm{m}$ de comprimento) com tempo de exposição de $6 \mathrm{~h}$, não diferenciando significativamente do substrato infusão de folhas de trigoágar (Tabela 2). O menor comprimento do tubo germinativo observado no tempo de exposição de $6 \mathrm{~h}$ ocorreu no substrato manitol-ágar, não diferindo significativamente do substrato frutose-ágar. No tempo de exposição de $12 \mathrm{~h}$, observou-se que o maior comprimento do pró-micélio foi proporcionado pelo substrato infusão de folhas de trigoágar (53,5 $\mu \mathrm{m}$ de comprimento), não sendo sobrepujado por nenhum dos demais substratos no mesmo tempo de exposição. $\mathrm{O}$ menor comprimento do pró-micélio para o tempo de exposição de $12 \mathrm{~h}$ foi observado no substrato frutose-ágar, não diferindo significativamente dos substratos, manitol-ágar, água-ágar e sacarose-ágar. No tempo de exposição de $24 \mathrm{~h}$, o substrato que proporcionou o maior comprimento do tubo germinativo foi a infusão de folhas de trigo-ágar $(52,0 \mu \mathrm{m}$ de comprimento), não diferindo significativamente do substrato extrato de folhas de trigo-ágar. No substrato frutose-ágar observouse o menor comprimento absoluto do tubo germinativo para o tempo de exposição de $24 \mathrm{~h}$.

Para a variável tempo de exposição observou-se que o substrato batata-sacarose-ágar (1/4), proporcionou o maior comprimento do tubo germinativo no tempo de exposição de $12 \mathrm{~h}$. Nos substratos frutose-ágar e infusão de folhas de trigo-ágar, o maior comprimento do tubo germinativo observado em ambos os casos foi nos tempos de exposição de 12 e $24 \mathrm{~h}$. Já para os substratos manitol-ágar e extrato de folhas de trigo-ágar, o maior comprimento do tubo germinativo observou-se em $24 \mathrm{~h}$ de exposição. Nos demais substratos água-ágar, batata-sacarose-ágar, sacarose-ágar e dextrose-ágar, não se observou diferenças significativas no comprimento do pró-micélio nos tempos de exposição testados.

$\mathrm{O}$ menor comprimento do tubo germinativo

TABELA 2 - Efeito de substratos e do tempo de exposição no comprimento do tubo germinativo $(\mu \mathrm{m})$ de uredosporos de Puccinia triticina

\begin{tabular}{llccc}
\hline \hline \multirow{2}{*}{ Substratos } & \multicolumn{3}{c}{ Tempo de exposição (h) } & \multirow{2}{*}{ Média } \\
\cline { 2 - 4 } & \multicolumn{6}{c}{$\mathbf{6}$} & $\mathbf{1 2}$ & $\mathbf{2 4}$ & \\
\hline 1- Àgua -ágar & $10,82 \mathrm{Ad}$ & $14,68 \mathrm{Aef}$ & $16,47 \mathrm{Ac}$ & 13,99 \\
2- Batata -sacarose -ágar (1/4) & $16,79 \mathrm{Bbc}$ & $28,52 \mathrm{Ac}$ & $20,29 \mathrm{Bbc}$ & 21,87 \\
3- Batata -sacarose -ágar & $22,07 \mathrm{Ab}$ & $26,07 \mathrm{Acd}$ & $25,85 \mathrm{Ab}$ & 24,66 \\
4- Sacarose -ágar & $17,69 \mathrm{Abc}$ & $15,97 \mathrm{Aef}$ & $22,22 \mathrm{Abc}$ & 18,63 \\
5- Dextrose -ágar & $14,52 \mathrm{Acd}$ & $20,63 \mathrm{Ade}$ & $17,26 \mathrm{Ac}$ & 17,47 \\
6- Frutose -ágar & $2,98 \mathrm{Be}$ & $11,99 \mathrm{Af}$ & $9,60 \mathrm{Ad}$ & 8,19 \\
7- Manitol -ágar & $1,17 \mathrm{Ce}$ & $13,17 \mathrm{Bf}$ & $18,57 \mathrm{Ac}$ & 10,97 \\
8- Infusão de folhas de trigo-ágar & $34,83 \mathrm{Ba}$ & $53,48 \mathrm{Aa}$ & $52,03 \mathrm{Aa}$ & 46,78 \\
9 Extrato de folhas de trigo-ágar & $38,69 \mathrm{Ba}$ & $40,80 \mathrm{Bb}$ & $50,77 \mathrm{Aa}$ & 43,42 \\
\hline Média & 17,73 & 25,03 & 25,90 & 22,9 \\
\hline Médias seguidas de mesma letra maiúscula na linha e minúscula na coluna não diferem & & & &
\end{tabular}

Fitopatol. Bras. 32(1), jan - fev 2007 
foi observado no substrato manitol-ágar no tempo de exposição de $6 \mathrm{~h}$ (1,2 $\mu \mathrm{m}$ de comprimento), não diferindo significativamente do substrato frutose-ágar no tempo de exposição de $6 \mathrm{~h}$.

Folhas de trigo, possivelmente, devem liberar compostos químicos solúveis em água capazes de induzir a germinação de uredosporos e estimular um maior crescimento do tubo germinativo, principalmente de fungos biotróficos. Fato semelhante foi relatado para Puccinia psidii Winter por Susuki et al. (1998) e Susuki \& Silveira (2003).

Embora se trate de um parasita biotrófico, houve resposta do substrato sobre o crescimento dos tubos germinativos indicando haver absorção e aproveitamento dos nutrientes disponíveis de modo a promover crescimento do tubo germinativo. Portanto, os substratos infusão de folhas ou extrato foliar, podem ser utilizados nos testes de sensibilidade de $P$. triticina a fungicidas em condições in vitro. Com esse procedimento, pode-se determinar a $\mathrm{DE}_{50}$ (concentração inibitória de $50 \%$ da germinação de esporos ou do comprimento micelial) de fungicidas a P. triticina e monitorar sua variabilidade em função da sensibilidade à substâncias químicas em função do tempo de exposição.

Os resultados obtidos permitem concluir que os substratos extrato de folhas de trigo-ágar e infusão de folhas de trigo-ágar promoveram o crescimento do tubo germinativo de $P$. triticina de maneira superior ao substrato padrão águaágar e com um tempo de exposição de $12 \mathrm{hs}$.

\section{REFERÊNCIAS BIBLIOGRÁFICAS}

ANONIMO. Reunião da Comissão Sul Brasileira de Pesquisa de Trigo. Indicações técnicas da comissão sul-brasileira de pesquisa de trigo. Passo Fundo, RS. Embrapa Trigo. 2003.

BARCELLOS, A.L., MORAES-FERNANDES, M.I.B. \& ROELFS, A.P. Ferrugem da folha do trigo (Puccinia recondita): durabilidade da resistência. Summa Phytopathologica 23:101-117. 1997.

REIS, E.M., CASA, R.T. \& MEDEIROS, C.A. Diagnose, patometria e controle de doenças de cereais de inverno. Londrina. ES Comunicação S/C Ltda. 2001.

SAMBORSKI, D.J. Wheat leaf rust. In: Roelfs, A.P. \& Bushnell, W.R. (Eds.) The cereal rusts: Disease, distribution, epidemiology, and control. Orlando FL. Academic Press 2v. 1985. pp. 39-59.

SHARVELlE, E.G. Chemical control of plant diseases. Fort Worth. Prestigie Press. 1969.

SUZUKI, M.S., SILVEIRA, S.F. \& ALFENAS, A.C. Germinação de urediniosporos de Puccinia psidii Wint. em meio de ágar com extratos foliares de goiaba, jambo ou eucalipto. Fitopatologia Brasileira 23:285. 1998. (Resumo)

SUZUKI, M.S. \& SILVEIRA, S.F. Germinação in vitro de urediniosporos de Puccinia psidii armazenados sob diferentes combinações de umidade relativa e temperatura. Summa Phytopathologica 29:188-192. 2003.

TORGESON, D.C. Determination and measurement of fungitoxicity. In: Fungicides. An advanced treatise. New York NY. Academic Press. pp. 93-123. 1967.

Recebido 21 Novembro 2005 - Aceito 12 Dezembro 2006 - FB 5114 